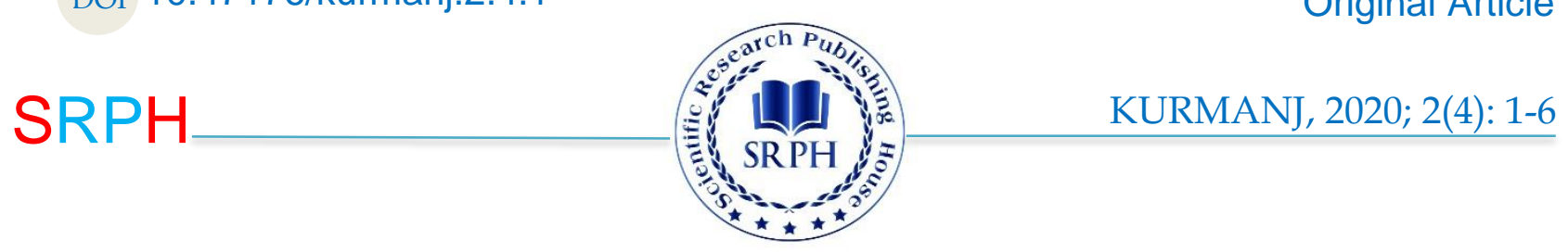

\title{
Test Anxiety: A Case of ESL Vocabulary Testing Using Multiple-Choice Items and Error Identification Tests
}

\author{
Esra Sipahi*
}

Ministry of Education Privacy Office, Turkey

\section{*Corresponding Author: \\ $\rtimes_{-}$Email:dresrasipahi@gmail.com}

Received: 05 September, 2020

Accepted: 30 October, 2020

Published: 15 November, 2020

\begin{abstract}
The current study seeks to discern the impact of test anxiety on English language students' test performance. The major instruments which helped gathering data were two different formats of vocabulary test and a questionnaire survey which identified the level of anxiety. Participants were fifty female English language learners who were studying at intermediate and upper-intermediate levels of English. These students were grouped into two groups of MC and EI according to their scores in the examinations they were given in the pre-test phase, multiplechoice test and error identification test. The survey after the pre-test indicated the level of anxiety these tests have brought. During a span of twenty-week period students received different teaching plans respectively. The same tests in pre-test were administered in the post-test phase and the questionnaire illustrated the level of anxiety after each student has received particular treatment. The findings showed that the level of test anxiety is higher in the group which received and tested on error identification format of vocabulary knowledge test. This increase of test anxiety was by definition significant in comparison with the other group, MC. The other important part of this study was coming to this conclusion that while students were given their particular teaching plans, debilitative anxiety still impedes them from having a strong and high performance which in turn needs more considerations from their teachers and examiners.
\end{abstract}

Keywords: Assessment, Vocabulary knowledge, Multiple-choice, Error Identification, Test anxiety

\section{Introduction}

\section{Theoretical and empirical background}

Assessment is a controversial issue; according to Black and Wiliam [1] it "is not a simple or innocent term" (p. 1); it casts a "long, dark shadow". Wiliam [2] defines assessment as "a procedure for eliciting evidence that can assist in educational decision making" (6). Additionally, this definition can cover various concepts of type, purpose and identity of the assessor. According to Shepard [3] an assessment which indeed assists the learner in his process of learning is instructionally supportive. In the end, in order to achieve this objective, assessment must be made more informative and social meaning of evaluation needs to be changed. Pervasive negative effects of tests ought to be discovered for a test in order to take advantage of them in enhancing the quality of learning and teaching.

According to Kaewmala [4], good tests reveal whether students are capable of applying their knowledge to their routine activities. Fulcher and Davidson [5] also believe that good tests bring about more positive effects in comparison with the negative ones. In line with these definitions, reliability and defensibility of the tests' construct are major facets of determining effectiveness of a test [6].

Carroll [7] describes a good test as: an experiment, in the sense that it must eliminate or at least keep constant all extraneous sources of variation. We want our tests to reflect only the particular kind of variation in knowledge or skill that we are interested in at the moment (p. 319). 
Aside from the definition of a good test, the impact of affective factors plays an important role in determining the consequences that a test brings. In terms of test anxiety, various factors such as differences in testing conditions, fatigue, and anxiety might have an impact on learners' test performance which in turn might vary from time to time [8]. Test anxiety is essentially a kind of performance anxiety - a feeling somebody may experience in an occasion where performance is truly essential or when there is pressure to do so.

The sources of test anxiety can be unclear or inaccurate instructions and inadequate time allocation which in turn affects test performance [9]. In other words, the higher gets the test anxiety, the more fluency is observed and the other way around [5].

Test format impacts learners' response to the test, counting test anxiety. With regard to different types of language tests, Resnick and Klopfer [10] believe that "fill in the bubble or multiple choice tests do not represent recent improvements in our understanding of what and how students learn" (p. 2). However, the above-mentioned kinds of assessments are neither considerably useful for gathering various types of information nor are adequately precise for assessing complex and varied student learning $[11,12,13,14$, 15]. Instruction and assessment must complement the complex nature of knowledge and take place in a form that makes the process of knowledge construction and transformation observable to some extent.

Hudesman and Wiesner [16] found that attrition and debilitating anxiety are not in any logical relationship with each other. facilitating anxiety however functions in terms of a scale to the language learners' ego strength in forecasting workshop attendance. Couch et al. [17] also revealed that a relationship does exist between the type of test anxiety and language learners' gender. The findings of the study conducted by Zatz and Chassin [18] also indicated that test anxiety and test performance are in direct correlation. It precisely revealed that the higher the test anxiety the poorer the students' results will be. There are also other researches which show that there is a relationship between test anxiety and test performance [19, 20].

The multiple-choice item is the ultimate archetype [21]. Multiple-choice tests are fast, easy and they can be scored objectively [22] and are more scorable than a response to an open-ended writing prompt [21].

Error identification items which aim at measuring language learners' knowledge of vocabulary and indirectly test their reading comprehension skill, consist of a complete sentence in with four vocabulary items underlined of which one is inappropriate in terms of meaning. Although this type of test is common in examining grammatical structures, the researchers modified its version of vocabulary knowledge.

The error identification format has been considered as being comfortable and easy to construct, as well as being efficient [23]. Nonetheless, error identification method can have negative effects because many students tend to regard every sentence as having an error [24] and they have to read and consider each response option carefully and draw on various kinds of grammatical knowledge to respond correctly [25].

Universities and institutions focus on determining learning accomplishment and knowledge using tests such as multiple-choice, essays, and short-answer tests. In this case, alternative assessment techniques such as portfolios, interviews, and journals are not commonly used in language learning contexts. Moreover, because there are institutions which require students accomplish and master particular levels and scores on examinations such as International English Language Testing System (IELTS) or Test of English as a Foreign Language (TOEFL), standardized tests are still of utmost significance to measure for assessment.

The impact of test formats on students' performances have not been investigated precisely throughout the literature, therefore the current study seeks to evaluate the use of multiple-choice test and error identification tests in testing vocabulary to find out the effect of test anxiety produced by the two types of test formats on learners' performance.

\section{Research questions}

1- Do the multiple-choice test and error identification test produce the same extent of test anxiety?

2- Is there any relationship between test anxiety produced by two test formats and test takers' performance?

\section{Purpose of the study}

The purpose of this study was to investigate the use of multiple-choice test and error identification tests in testing vocabulary knowledge to find out the effect of test anxiety produced by the two types of test format on learners' performance.

\section{Research Methodology}

\section{Participants}

Fifty English language learners were selected as the participants of the current study randomly from Shokouh language institute in Tonekabon, Iran. Students were aged between 16 to 24 . They were all female students and were studying at the intermediate and upper-intermediate level of English language.

\section{Instruments}

\section{Vocabulary knowledge test (Pre-test and post-test)}

A vocabulary test of 60 questions was designed using the book Oxford Word Skills by Ruth Gairns and Stuart Redman [26] to test students' vocabulary knowledge. This test consisted of 30 multiple-choice 
items and 30 error identification items which requires students to choose the mistakenly placed word choice. This test took an approximate time of thirty minutes. It was administered twice, at the beginning of the course as the pre-test to identify students' knowledge of vocabulary items and also at the end of their term as the post-test in order to discern the effect of the treatment. According to the results of the pre-test phase, students were assigned to two groups of 25 participants each.

\section{Teaching plans}

Forty teaching plans were designed to develop students' knowledge of vocabulary. Among them, twenty teaching plans were designed using multiplechoice exercises applying to the group which will be called hereafter as multiple-choice group (MC group). The other part of this plan was designed using 20 error identification exercises that would be implemented to the other group, referred to as error identification group (ER group).

Although teaching plans consisted of different test formats, multiple-choice and error identification, they were aimed at building up the same vocabulary families, i.e. learning, people, the world around us, daily life, getting things done, and describing things. Each group spent twenty 1.5-hour sessions for the teaching plans, i.e. one and a half hour for each teaching plan in each group.

\section{Test anxiety questionnaire}

A 5-point Likert scale type anxiety questionnaire was adapted, based on the model applied by Scott [27] and Cassady and Johnson [28] in order to identify the degree of test anxiety each participant has encountering the two test types, multiple-choice and error identification, before and after the treatment period. This questionnaire was consisting of 20 items related to how one generally feels when taking the two test formats. The items of this questionnaire ranged from "Strongly Disagree" to "Strongly agree" with values 1-5 assigned to them respectively. It is worth noting that the items were translated into Farsi in order to avoid any possible misunderstandings.

\section{Procedure}

The vocabulary test was administered to all 50 students in the first week, in order to measure their vocabulary knowledge and assign them to two groups. Then the anxiety questionnaire was given to them to identify their attitudes towards two different test formats, multiple-choice and error identification tests. During their course, the two groups were offered the two teaching plans applying error identification exercises and multiple-choice exercises in order to build up their knowledge of vocabulary items.

At the end of their course, the same test that was administered in the pre-test phase was once more given to both groups to investigate the progress in their vocabulary knowledge. Likewise, the anxiety questionnaire was then administered with the same procedure and intention in the pre-test phase.

\section{Results and Discussion}

The level of anxiety that has been produced by the two control and experimental groups in terms of multiplechoice and error identification vocabulary tests are shown in Table 1.

Table 1

Two subject groups' test anxiety produced by multiple-choice and error identification formats.

\begin{tabular}{lccccccc}
\hline & \multicolumn{2}{c}{ Before treatment } & \multicolumn{2}{c}{ After treatment } & \multicolumn{2}{c}{ Paired-sample t-test } \\
\cline { 2 - 7 } & $\overline{\boldsymbol{x}}$ & S.D. & $\overline{\boldsymbol{x}}$ & S.D. & & t-value & 2-tail sig \\
\hline MC version & 3.12 & 0.29 & 2.53 & 0.11 & 0.59 & -1.611 & 0.175 \\
EI version & 2.98 & 0.61 & 2.13 & 0.38 & 0.85 & -0.989 & 0.347 \\
MC version & 3.07 & 0.37 & 2.71 & 0.29 & 0.36 & -1.009 & 0.098 \\
EI version & 3.21 & 0.52 & 3.01 & 0.34 & 0.20 & -1.059 & 0.164 \\
\hline
\end{tabular}

According to the information illustrated in Table 1, the level of anxiety in both groups was approximately the same (although the highest level of anxiety was observed in MI group and the other group had lower level of anxiety). However, the results after the treatment are not consistent with the results before the treatment. Students' level of anxiety has dropped in all tests albeit this decrease was far more considerable in the multiple-choice group and the decreases were 0.59 and 0.85 respectively. This decrease is significant.
Consequently, the MC group were less anxious after the 20-week treatment in comparison with their counterpart EI group who were still more anxious although they were experiencing a lower level of anxiety compared to their pre-treatment period. With this regard, it is shown that practice has had a positive impact on learners' level of anxiety. In other words, as they practice more and receive the respective instructions they will experience lower level of anxiety. This familiarization with the terminologies has helped the students be less anxious after the second test. 
Cassady and Johnson [28] also prove it, showing that test anxiety affects test performance.

With the same regard, Young [29] believe that familiarization with the topic can help the learners reduce their level of anxiety however the findings of the current study added to the literature by showing that this reduction can be significant in particular areas. According to this, the practitioner would expect lower level of anxiety as he gets the learners familiar with the topic and assumes still more anxiety giving error identification tests rather than multiple-choice items which might itself be a result of students' familiarity with this type of question during their studies.

The other important part of the current study was the relationship between test anxiety and test performance. In order to observe whether a significant relationship exists between students' performance and the level of test anxiety, their scores in both type of vocabulary knowledge examinations, the multiple-choice and error identification, and their level of anxiety were analyzed using Product Moment Correlation Coefficient Test. Table 2 shows the relationship between students' scores and their level of anxiety after the tests.

Table 2

Relationship between test scores and test anxiety.

\begin{tabular}{lcc}
\hline & \multicolumn{2}{c}{ Level of test anxiety } \\
\cline { 2 - 3 } & Before treatment & After treatment \\
\cline { 2 - 3 } & Pearson $\mathbf{~}$ & Pearson $\mathbf{~}$ \\
\hline MC format & 0.121 & 0.011 \\
EI format & $-0.612^{*}$ & -0.235 \\
MC format & 0.281 & -0.183 \\
EI format & $-0.803^{*}$ & -0.074 \\
\hline
\end{tabular}

According to Dörnyei [30], in order to examine the relationship between two variables we should perform correlation analysis since it allows us to look at two variables and evaluate the strength and direction of their relationship or association with each other. With regard to calculating the correlation between these two variables, Pearson product moment correlation type was being used which, according to Dörnyei [30], is "the standard type, computed between two continuous variables. When we talk about 'correlation' in general, this is what we usually mean" (p. 224). The Pearson correlation coefficient, $r$, can take a range of values from +1 to -1 . A value of 0 indicates that there is no association between the two variables. A value greater than 0 indicates a positive association; that is, as the value of one variable increases or decreases, so does the value of the other variable. A value less than 0 indicates a negative association. That is, as the value of one variable increases, the value of the other variable decreases. According to Mackey and Gass [31] the correlation coefficient (which ranges from +1 to -1 ) gives information about the extent to which there is a linear relationship between the variables.

Among all the correlations shown above in the table, those which are related to students' performance before receiving the treatment were significant while the rest were not considerably significant.

In both MC and EI groups the correlation between students' scores in error identification test and their level of anxiety was significant. According to the table, these statistics were -0.612 and -0.803 which showed that a strong negative correlation does exist between the two variables of test performance and level of anxiety. In other terms, as students' test performance increase their level of anxiety will reduce and vice versa. This significant findings, however, is missing for the multiple-choice item formats and is merely observed in error identification version of the vocabulary test which in turn can be explained due to students' familiarization with the multiple-choice format.

This anxiety which is risen because of the test is known as debilitative anxiety which Nugent [32] defines it as "An anxiety felt by a person that they see as interfering with their performance, such as being psyched out or not in the zone" (para. 1).

The findings of the study conducted by Trifoni and Shahini (2011) approves the correlation that is observed between the test performance and the test anxiety for error identification format of vocabulary test.

\section{Conclusion}

The present study sought to establish a relationship between test performance in different formats of vocabulary knowledge, namely multiple-choice format and error identification format and the level of anxiety any of these tests causes. To this end pre and posttest phases were designed and the participants received the respective treatment during their course which in turn aimed at preparing them for the final tests.

The findings supported previous researches which have revealed a negative relationship between test anxiety and language learners' performance [e.g., 19, 33, 34]. All these researchers have drawn the conclusion that students' performance and test anxiety level have a reverse ratio, meaning that when test anxiety level 
increases, students' performance decreases and the other way around.

This study, as delineated in the previous section, had two significant findings. The first was that, in vocabulary knowledge test the level of anxiety that error identification format produces for the language learners is higher than that of multiple choice format. On the other hand, this level of anxiety is apparently significant. This significance is defined in terms of students' familiarization with this type of assessment although both groups received treatments over a twenty-session period.

The current research study also indicated that the more anxiety a test produces the poorer performance the student will have. This is defined in terms of debilitative anxiety which stands for this in adverse relationship between students' performance and test anxiety.

These findings help English language practitioners and evaluators to adjust their method of presentation to the assessment method and rely more on students' familiarization in case they seek a higher test performance. In addition, modifying test format can lead in lower test performance and requires teachers emphasize on the modified version. The knowledge of vocabulary is usually assessed using multiple choice questions or test which require the learners translate each terminology while this modified version, error identification test, gets the students to have a knowledge of both the word and its pragmatic usage as well. The correct word choice is one major point which needs more consideration.

\section{References}

1. Black P, Wiliam D. In praise of educational research: Formative assessment. Br Educ Res J. 2003; 29(5): 623637.

2. Wiliam D. Towards a philosophy for educational assessment. $\mathrm{Br}$ Educ Res Assoc 1994; http://www.kcl.ac.uk/depsta/education/publications/ BERA_94.pdf

3. Shepard LA. The role of assessment in a learning culture. Educ Res. 2000; 29(7): 4-14.

4. Kaewmala, The education failure- part 2: Test score, standards and accountability. 2012.

5. Fulcher G, Davidson F. Language testing and assessment. London, NY: Routledge. 2007.

6. McNamara T, Roever C. Language testing: The social dimension. John Wiley \& Sons. 2006; 1.

7. Carroll JB. Fundamental considerations in testing for English language proficiency of foreign students. Reprinted in Allen HB, Campbell RN. (eds) (1965), Teaching English as a Second Language: A Book of Readings. New York: McGraw Hill, 1961; 313-330.

8. Bachman LF. Fundamental considerations in language testing. Oxford University Press. 1990.
9. Madsen HS. Techniques in Testing. Oxford University Press, 200 Madison Ave., New York. 1983.

10. Resnick LB, Klopfer LE. Toward the thinking curriculum: Current cognitive research. 1989 ASCD Yearbook. Association for Supervision and Curriculum Development, 1250 N. Pitt St., Alexandria, VA 223141403.

11. Aschaber PR. Performance Assessment: State Activity. Interest Conc Appl Meas Educ. Say1: 1991; 4: 275288.

12. Brown JD, Hudson T. The alternatives in language assessment. TESOL Q. 1998; 32(4): 653-675.

13. Genesee F. Bilingual first language acquisition: Exploring the limits of the language faculty. Ann Rev Appl Linguist. 2001; 21: 153-168.

14. Huerta-Macias A. Alternative assessment: Responses to commonly asked questions. TESOL J. $1995 ; 8-27$.

15. O’Malley JM, Pierce LV. Authentic assessment for English language learners: Practical approaches for teachers. New York: Addison-Wesley Publishing Company. 1996.

16. Hudesman J, Wiesner E. Facilitating and debilitating test anxiety among college students and volunteers for desensitization workshops. J Clin Psychol. 1978; 34(2): 484-486.

17. Couch JV, Garber TB, Turner WE. Facilitating and debilitating test anxiety and academic achievement. Psychol Rec. 1983; 33(2): 237-244.

18. Zatz S, Chassin L. Cognitions of test-anxious children under naturalistic test-taking conditions. $J$ Consult Clin Psychol. 1985; 53(3): 393.

19. Hembree R. Correlates, causes, effects, and treatment of test anxiety. Rev Educ Res. 1988; 58(1): 4777.

20. Birjandi P, Alemi M. The impact of test anxiety on test performance among Iranian EFL learners. Broad Res Artif Intell Neurosci. 2010; 4.

21. Fulcher G. Practical language testing. Routledge. 2013.

22. Bailey KM. The use of diary studies in teacher education programs. Sec Lang Teach Educ. 1990; 215226.

23. Nihae NI, Charmaine T. Multiple-choice and error recognition tests: effects of test anxiety on test performance. Int J Eng Lang Educ. 2014; 2(2): 78-88.

24. Heaton JB. Writing English Language Test (New Edition). 1988.

25. Gergely G. Learning about versus learning from other minds: Human pedagogy and its implications. 2007.

26. Gairns R, Redman S. Oxford word skills: Intermediate. Oxford University Press. 2008.

27. Scott ML. Student affective reactions to oral language tests. Lang Test. 1986; 3(1): 99-118. 
28. Cassady JC, Johnson RE. Cognitive test anxiety and academic performance. Contemp Educ Psychol. 2002; 27(2): 270-295.

29. Young DJ. Affect in foreign language and second language learning. Boston, MA: McGraw-Hill. 1999.

30. Dörnyei Z. Research methods in applied linguistics. 2012.

31. Mackey A, Gass SM. Second language research: Methodology and design. Routledge. 2015.
32. Nugent Pam MS. Debilitative anxiety. PsychologyDictionary.org,

2013; https://psychologydictionary.org/debilitativeanxiety/

33. Hancock DR. Effects of test anxiety and evaluative threat on students' achievement and motivation. $J$ Educ Res. 2001; 284-290.

34. Chapell M. et al. Test anxiety and academic performance in undergraduate and graduate students. $J$ Educ Psychol. 2005; 97: 268-274.

\section{KURMANJ}

Copyright: (C) 2020 The Author(s); This is an open-access article distributed under the terms of the Creative Commons Attribution License (http://creativecommons.org/licenses/by/4.0), which permits unrestricted use, distribution, and reproduction in any medium, provided the original work is properly cited.

Citation: Sipahi E, Test Anxiety: A Case of ESL Vocabulary Testing Using Multiple-Choice Items and Error Identification Tests. KURMANJ, 2020; 2(4): 1-6.

https://doi.org/10.47176/kurmanj.2.4.1 